\title{
Arquitetura e Sustentabilidade: $O$ uso de óleo de cozinha usado na produção de adobes
}

Architecture and Sustainability: The use of cooking oil used in adobe production

"Arquitectura y sostenibilidad: el uso del aceite de cocina utilizado en la producción de adobe"

\section{Bruno Humberto da Silva} Discente, FAAC, UNESP, Brasil. Bruno.geounesp@hotmail.com

\section{Maximiliano dos Anjos Azambuja} Professor Doutor, UNESP, Brasil. m.azambuja@unesp.br

Rosane Aparecida Gomes Battistelle Professora Doutora, UNESP, Brasil. rosane.battistelle@unesp.br 


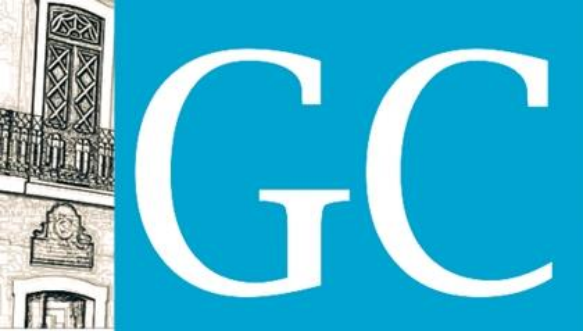

Revista Nacional de

Gerenciamento de Cidades
ISSN 2318-8472

v. 07, n. 52,2019

natura é um dos principais commodity de exportação do agronegócio brasileiro.

A produção mundial de óleo vegetal alcançou um recorde de 197 milhões de toneladas na safra 2017/2018, aponta o United StatesDepartamentofAgriculture (USDA) apudGottems (2018), aumentando em $4 \%$ do ano de 2018, esse crescimento recorde favoreceu a economia de diversos países como Brasil, que incorporou e incentivou a produção de biodiesel nos últimos 14 anos.

Com o crescimento de aproximadamente $7,6 \%, 0$ óleo de palma ainda continua sendo o mais consumido no mundo, em contra partida ao óleo de soja, 63 que no Brasil, de longe é o óleo comestível mais consumido, com uma produção de 8,5 milhões de toneladas ao ano, com um aumento de $3,7 \%$, destacando desta forma a soja como um produto de alto valor de mercado, destinado a diversos usos.

A cadeia produtiva do óleo de cozinha, neste caso, o óleo de soja, tem impacto diretamente sobre o meio ambiente a agroindústria de oleaginosas, afirmando as informações da ABIOVE, Gonçalves e Chaves (2014), consideram que apesar do óleo vegetal ser menos tóxico que o óleo fóssil, ambos são poluentes, a contaminação dos recursos d'agua com óleo de cozinha encarece o tratamento dá água, cria entupimentos nos encanamentos, e pode dificultar a entrada de luz nos rios, lagos e oceanos, atrapalhando a oxigenação da água, causando a mortandade de peixes, e outros animais da fauna aquática, pois os óleos e as graxas como hidrocarbonetos em excesso interferem no processo biológico ocasionando a ineficiência ou eutrofização da água por microrganismo, comprometendo todo um ecossistema e na cadeia alimentar, bem como na economia visto que a pesca é uma importante atividade econômica no país.

Zhang et. al. (2003 B) apud Gonçalves e Chaves (2014), veem a reciclagem do óleo vegetal como uma alternativa eficiente para a produção do biodiesel, a transesterificação, do óleo revela um importante caminho dentro da logística reversa, dos óleos vegetais usados.

Para Gonçalves e Chaves (2014) a logística reversa considera os interesse da sociedade, resultados positivos na economia, entre, resgate de capital destinado á custos de produção, e que pode retornar produtos, reduzircustos, reciclagem de materiais, reutilização, reparo a danos na cadeia produtiva e novas propostas de produção, envolvendo novos agente como o Estado e uma população indiretamente ligada, a cadeia reversa, ou produtiva, criando ao setor privado competitividade no mercado e boa imagem, em especial ao destaque sobre o papel de responsabilidade ambiental.

\section{OBJETIVOS}

Entender a influência de biopolímeros como óleo cozinha usado nas propriedades físicas e mecânicas dos adobes com Latossolo de Bauru, adicionando solo Nitossolo de Barra Bonita, tornando-os capazes de resistir a absorção d'água, e a resistência a compressão para serem usados na construção de edifícios. 


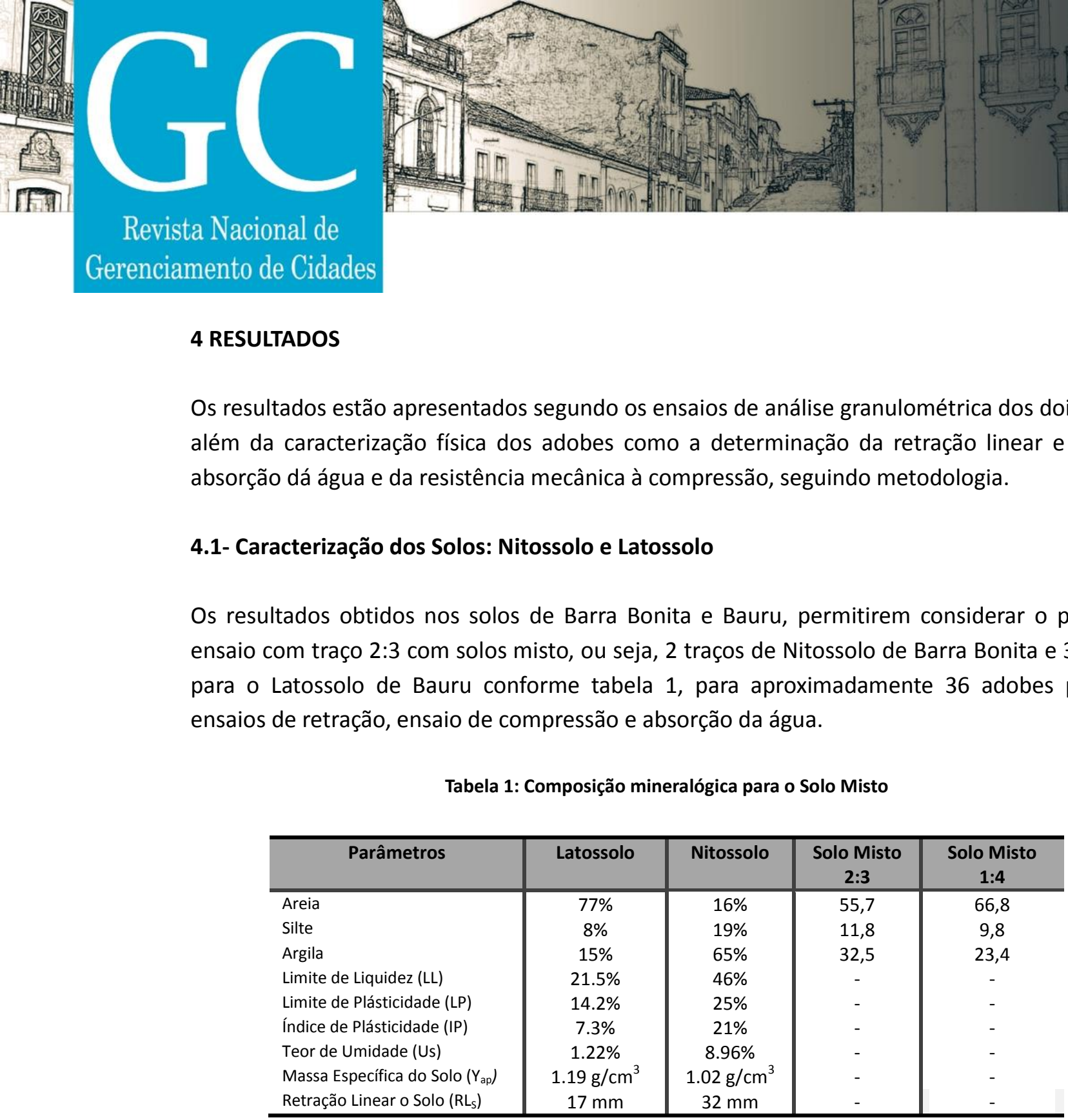

Os resultados estão apresentados segundo os ensaios de análise granulométrica dos dois solos, além da caracterização física dos adobes como a determinação da retração linear e média, absorção dá água e da resistência mecânica à compressão, seguindo metodologia.

\section{ANAP}

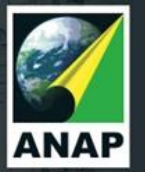

Fonte:Autores

\subsection{Determinação da retração linear e média}

Para a determinação da retração linear e média foram medidas todas as faces conforme figura 4 ecalculadas encontrando assim os resultados necessários. 


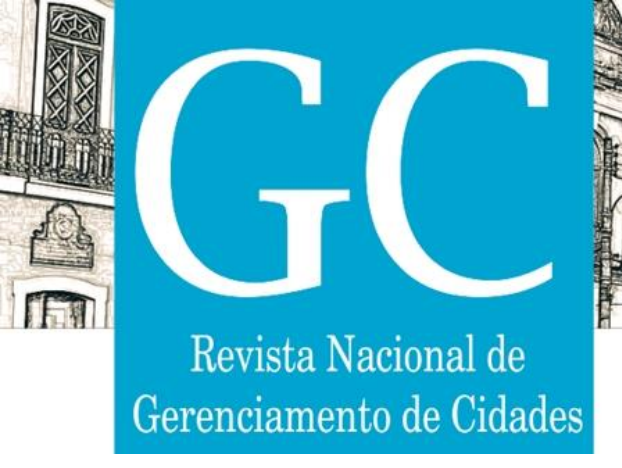

Figura 8: Adobes após 24 horas imersos em água, respectivamente $0 \%$ OCU, $2 \%$ OCU e $4 \%$ OCU.
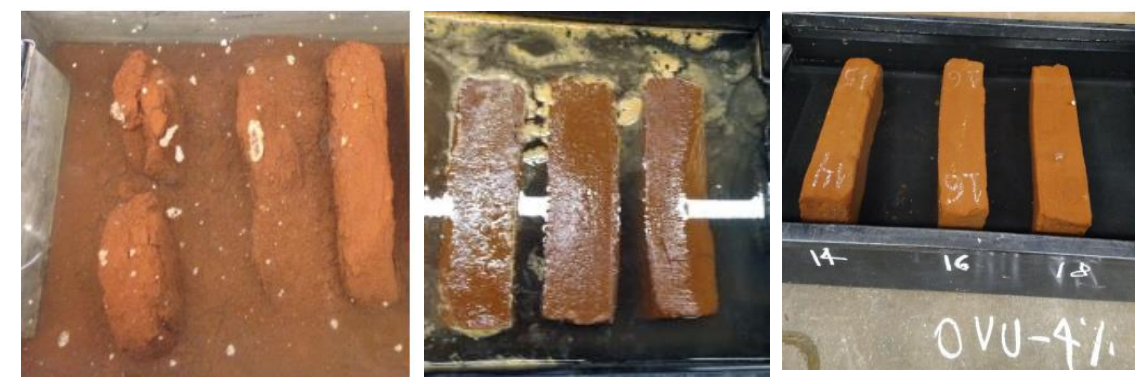

Fonte: Autores

Os destaques apresentados demonstram a eficácia dos biopolímeros, porém devido a inexistência de normas adequadas para adobes, porém consideram as normas NBR 10834 (ABNT 2012) para tijolos de solocimento, que aufere a utilidade para os materiais com valores de absorção de até aproximadamente $20 \%$, os percentuais adequados para a produção dos adobes incorporando $\mathrm{OCU}$, foram de $4 \%$, entretanto, os traços de $2: 3$, devido a retração são ineficazes para uso.

\section{CONCLUSÃO}

Analisando os fenômenos referentes ao déficit habitacional no Brasil, e as referências bibliográficas sobre a questão da construção civil e os impactos ambientais envolvidos na indústria civil no país, as averiguações sobres novas metodologias e materiais construtivos são necessárias. Os setores voltados para Arquitetura e da Engenharia têm demonstrado grande interesso sobre a expansão da bioconstrução, fator fundamental para este processo, que surge como proposta de baixo custo para construção de edificações sustentáveis. Os aspectos voltados para Arquitetura com Terra e suas potencialidades, fomentam pesquisas em todos os setores da construção civil.

Este projeto destacou a importância de se repensar na problemática que envolve a questão da sustentabilidade e como o campo da pesquisa pode contribuir com novas propostas, como por exemplo, a produção de materiais milenares como o adobe.

Os traços definidos deste projeto foram 1:4 e 2:3, os resultados apresentados por ambos foram aparentemente parecidos, entretanto o traço 2:3 demonstrou alta retração (de 4,15\% 0\%OCU, para 4,32\% - 4\%OVU) e trinca nos tijolos, além de queda na resistência a compressão ( de 1,93 MPa para 0,85 MPa) e alta absorção de água.( 100\% - 0\%OCU, 45,65\% - 2\% OCU e 16,04- 4\% OCU). O traço 1:4 foi definido para regularizar a composição granulométrica, que obtiveram resultados um pouco mais baixo em relação a retração, porem houve uma queda gradativa com a incorporação dos biopolímeros. O teste de absorção foi surpreendente, pois com este traço e um valor de $4 \%$ de $O C U$, os tijolos não tiveram sua geometria inicial modificada. Devido as estas condições os adobes 1:4 com percentual de $4 \%$ de OCU, foram os adobes selecionados como material construtivo, porém devido a sua menor resistência a compressão, ele pode ser usado como elemento de vedação, e não estrutural. Para solucionar 


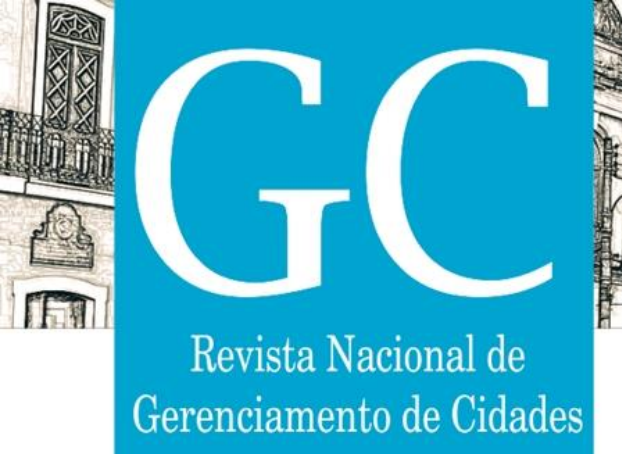

estes problemas novas propostas de projetos estarão em andamento, resgatando novas bibliografias, a próxima etapa será realizar a adição de fibras para estabilização, controle da retração e aumento da resistência dos tijolos.

\section{REFERÊNCIAS BIBLIOGRÁFICAS}

Associação Brasileira de Normas Técnicas. NBR 10834: Bloco de solo-cimento sem função estrutural - requisitos. Rio de Janeiro, 2012. 5 p.

Associação Brasileira de Normas Técnicas. NBR 13555: Solo-cimento - determinação da absorção de água método de ensaio. Rio de Janeiro, 2012. $1 \mathrm{p}$.

BATTISTELLE, R. A. G. Análise da viabilidade técnica do resíduo de celulose e papel em tijolos de adobe. Tese (Doutorado em Ciências da Engenharia Ambiental) - Escola de Engenharia de São Carlos, Universidade de São Paulo, São Carlos, 2002. Disponível em: <https://teses.usp.br/teses/disponiveis/18/18139/tde-08122016-113526/ptbr.php>. Acesso em: 20 de março de 2018.

BECKER, D. F; ALMEIDA, J; GOMÉZ, W.H; PHILOMENA, A.L; RAMPAZZO, S.E; REIGOTA, M; VARGAS, P.R; Desenvolvimento Sustentável: Necessidadee/ou Possibilidade? - 2 ed. EDUNISC.Santa Cruz do Sul. 1999.

BOFF, L; Sustentabilidade: $O$ que é, o que não é . 1ạed. Vozes. Petrópolis, 2012. 200p.

CARDOSO, F. F.; ARAUJO, V. M. Redução de Impactos Ambientais do Canteiro de Obras. In: PROJETO para Construção Habitacional Mais Sustentável. São Paulo: Edusp, 2004. Disponível em: <http://www.scielo.br/scielo.php?script=sci_nlinks\&pid=S1678-8621201700040007900008\&lng=en> Acesso> 12 Jun. 2019.

CARVALHO, T. M. P.; LOPES, W. G. R. A arquitetura de terra e o desenvolvimento sustentável na construção civil. VII CONNEPI Palmas, TO. 2012.

EIRES, R. M. G. Construção em terra: desempenho melhorado com incorporação de biopolímeros. Tese (Doutorado em Engenharia Civil - Materiais de Construção) - Escola de engenharia - Universidade do Minho, Portugal. 2012. Disponível em: <http://repositorium.sdum.uminho.pt/handle/1822/21010>. Acesso em 13 de Setembro de 2018.

EIRES, R.; CAMÕES,; JALALI, S. Optimização do desempenho de construção em terra com recurso a bio-polímeros. Universidade do Minho - Departamento de Engenharia Civil. In: Terra em seminário 2010. Coimbra - Portugal, 2010. Ed. Argumentum. p. 168-171

FARIA, O. B. Utilização de macrófitas aquáticas na produção de adobe: um estudo de caso no Reservatório de Salto Grande (Americana-SP). Tese (Doutorado em Ciências da Engenharia Ambiental) - Escola de Engenharia de São Carlos, Universidade de São Paulo, São Carlos, 2002. Disponível em: <http://www.teses.usp.br/teses/ disponiveis/18/18139/tde-10022003-103821/>. Acesso em: 02 de Fevereiro de 2018.

FARIA, O. B.; OLIVEIRA, B. M. de; TAHIRA, M.; BATTISTELLE, R. A. G. Realização do programa interlaboratorial PROTERRA em Bauru-SP (Brasil). In: TERRABRASIL 2008, São Luiz - Maranhão, p. 39-50. Disponível em: <https://www.academia.edu/35731095/Actas_7_SIACOT._Brasil_2008>. Acesso em: 08 de Fevereiro de 2018.

FUREGATTI, S. A; RODRIGUES, R. A. Granulometria. Limite de Consistência e Classificação de Solos : Mecânica dos Solos e Fundações. 01 Mar. 2018 - 30 Jun. 2018. Notas de Aulas. 3. Faculdade de Engenharia de Bauru. Bauru. 2018. 14p.

Gonçalves, M. F. S; CHAVES, G. L. D. Perspectiva do Óleo Residual de Cozinha (ORC) no Brasil e suas dimensões na Logística Reversa. Revista Espacios. Espacios. Vol. 35 (№ 8) Año 2014.

GOTTEMS, L; USDA revisa para cima projeções para soja brasileira. KLAFFMAN Group Notícias. Disponível em <http://portalklff.com.br/noticia/usda-revisa-para-cima-projecoes-para-soja-brasileira-1060065> Acesso em 10 Jan. 2019. 


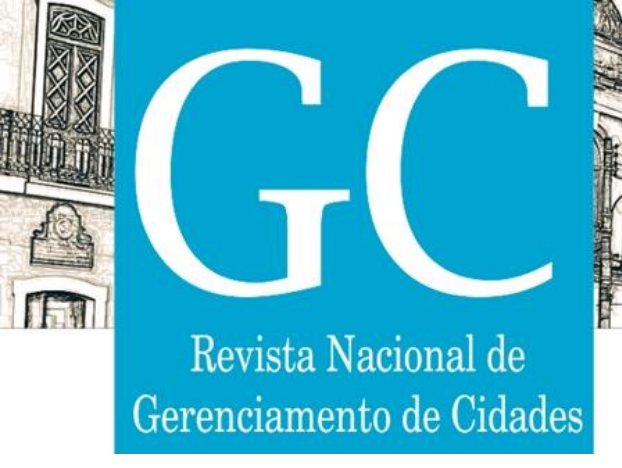

GRÜNBERG, P. R. M.; MEDEIROS, M. H. F.; TAVARES, S. F..Certificação ambiental de habitações: comparação entre LEED for homes, Processo Aqua e Selo Casa Azul. Revista Ambiente \& Sociedade: São Paulo, v. 17, n. 2, pp. 195-214, 2014.

LEPSCH, I. F. Formação e conservação dos solos. 1. Ed. Oficina de Textos. São Paulo. 2002. 178 p.

MARICATO, E. As ideias fora do lugar, e o lugar fora das ideias. In: ARANTES, O. B. F.; VAINER, C.; MARICATO, E. A cidade do pensamento único. Desmanchando consensos. Coleção Zero à esquerda, Petrópolis, Vozes, 2000.

MAURY, M. B., BLUMENSCHEIN, R.N. Produção de cimento: Impactos à saúde e ao meio ambiente. $\begin{array}{lllll}\text { Sustentabilidade em } & \text { Debate. } & \text { Disponível } & \text { em: }\end{array}$ <http://seer.bce.unb.br/index.php/sust/article/view/7199/5666>Acesso em 18 de out. 2018.

MIKHAILOVA, I. Sustentabilidade: Evolução dos Conceitos Teóricos e os Problemas da Mensuração Prática. Universidade Federal do Mato Grosso do Sul. Revista Economia e Desenvolvimento, $n^{\circ} 16,2004$. Disponível em < http://w3.ufsm.br/depcie/arquivos/artigo/ii_sustentabilidade.pdf> Acesso em 12 nov. 2018

MILANEZ, B; LOSEKANN C; ( Org.). Desastre no Vale do Rio Doce: antecedentes, impactos e ações sobre a destruição- Rio de Janeiro: Folio Digital: Letra e Imagem, 2016. Disponível em:<http://ftp.medicina.ufmg.br/osat/ebook/2017/desastre-no-vale-do-rio-doce-16-03-2017.pdf>Acesso 15 Mai. 2019.

MINKE, G. Manual de construccionentierra. Ed. Nordan-Comunidad, Montevideo, Uruguai, 2001.

Morrison, R.; Boyd, R.; Química Orgânica, 13a ed., Fundação Calouste Gulbenkian: Lisboa, 1996.

NETO, P. R. C.; ROSSI, L. F. S.; ZAGONEL, G. F.; RAMOS, L. P. Produção de biocombustível alternativo ao óleo diesel através da transesterificação de óleo de soja usado em frituras. Curitiba. In: Química Nova. v. 23, n. 4.2000. Disponível em:<http://quimicanova.sbq.org.br/detalhe_artigo. asp?id=1454>. Acesso em: 08 mar. de 2019

NEVES, C. M. M.; FARIA, O. B.; ROTONDARO, R.; CEVALLOS, P. S.; HOFFMANN, M. V. Seleção de solos e métodos de controle na construção com terra: práticas de campo. PROTERRA, 2009. Disponível em: <https://www.academia.edu/35702223/Sele\%C3\%A7\%C3\%A3o_de_solos_e_m\%C3\%A9todos_de_controle_na_con stru\%C3\%A7\%C3\%A3o_com_terra._Pr\%C3\%A1ticas_de_campo $>$. Acesso em: 11 de Fevereiro de 2018.

NEVES, C.; FARIA, O. B. (Org.). Técnicas de construção com terra. Bauru, SP: FEB-UNESP/PROTERRA, 2011. p. 9-25. Disponível em: <https://www.academia.edu/35702333/T\%C3\%A9cnicasdeconstru\%C3\%A7\%C3\%A3ocomterra>. Acesso em: 11 de Fevereiro de 2018.

POPP, J. H. Meteorização das Rochas: Os Solos. In: POPP, J.H. Geologia Geral. 5ąed:- Rio de Janeiro. LTC. 2002. p.5686

ROTH, C; GARCIA, C. Construção Civil e a Degradação Ambiental. Desenvolvimento Em Questão, 7(13), 111-128. 2011. Disponível em www.revistas.unijui.edu.br/index.php/desenvolvimentoemquestão/article/view/1 69/ 125 Acesso em 10 Set. 2018.

SANTOS, H. G. dos; JACOMINE, P. K. T; ANJOS, L. H. C. dos; OLIVEIRA, V. A. de; LUMBRERAS, J. F.; COELHO, M. R.; ALMEIDA, J. A. de; ARAUJO FILHO, J. C. de; OLIVEIRA, J. B. de; CUNHA, T. J. F.Sistema Brasileiro de Classificação de Solos. Embrapa Solos. Brasília. 2018. Disponível em:<https://www.embrapa.br/busca-de-publicacoes//publicacao/1094001/brazilian-soil-classification-system>. Acesso 12 de Nov. 2018.

WUST, E. Estudo da viabilidade técnico-científica da produção de biodiesel a partir de resíduos gordurosos. Mestrado, Centro de Ciências Tecnológicas da Universidade Regional de Blumenau - FURB, Blumenau, 2004 